\title{
CHANGES IN NATURAL OSL SENSITIVITY DURING SINGLE ALIQUOT REGENERATION PROCEDURE AND THEIR IMPLICATIONS FOR EQUIVALENT DOSE DETERMINATION
}

\author{
ASHOK K. SINGHVI ${ }^{1}$, STEPHEN C. STOKES ${ }^{2, \text { a }}$, NAVEEN CHAUHAN ${ }^{1}$, YOGESH C. NAGAR ${ }^{1, b}$ \\ and MANOJ K. JAISWAL ${ }^{1, c}$

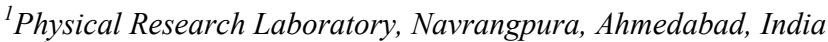 \\ ${ }^{2}$ Department of Geography, South Parks Road, Oxford, UK, \\ anow moved to private life \\ ${ }^{b}$ Present Address: Defense Research and Development Organization, Manali, India \\ ${ }^{c}$ Present address: Department of Earth Sciences, Indian Institute of Science and Education Research \\ (IISER-Kolkatta), Mohanpur campus, BCKV Main Office, Nadia, West Bengal, India
}

Received 2 December 2010

Accepted 25 December 2010

\begin{abstract}
Measurement of low temperature $\left(90^{\circ} \mathrm{C}-120^{\circ} \mathrm{C}\right)$ Thermoluminescence (TL) sensitivity of natural quartz samples subjected to pre-heating and optical stimulation indicate that significant sensitivity changes can occur during measurement of the natural Optically Stimulated Luminescence (OSL). During the measurement of natural signal, the luminescence sensitivity of samples can change by $40 \%$. The sensitivity changes both during the initial preheat and the measurement of natural OSL. The currently used version of Single Aliquot Regeneration (SAR) protocol measures and corrects for the sensitivity changes after preheat and readout of natural OSL. However, it does not take into account the changes in sensitivity during the readout of the natural signal.

We therefore developed a correction procedure so that both the natural and the regenerated OSL intensities can be measured and plotted with the same sensitivity and suggest that in the absence of such a correction, a considerable fraction of the SAR based ages could have systematic errors. The correction for the sensitivity is based on the use of sensitivity of $110^{\circ} \mathrm{C}$ TL quartz peak, which is correlated to OSL signal (Murray and Roberts, 1998). The use of $110^{\circ} \mathrm{C}$ peak provides a reasonable measure of the changes in OSL sensitivity of quartz. A modified Natural Sensitivity Corrected-SAR (NSC-SAR) procedure, that comprises the measurement of, 1) the $\mathrm{TL}$ intensity of $110^{\circ} \mathrm{C}$ peak for a test dose on sample as received (i.e. natural sample) and, 2) the sensitivity of the $110^{\circ} \mathrm{C}$ peak of the same sample after the preheat and read out of the natural OSL, is proposed. This ratio, termed as Natural Correction Factor (NCF), then provides a way to correct for sensitivity changes. Results on samples from diverse depositional environments indicated that the NSC-SAR consistently (without exception) provided improved distribution in paleodoses i.e. a lower scatter compared to the standard SAR protocol. In addition, the use of this protocol also resolved anomalous cases where the intensity of natural OSL was significantly above the saturation intensity of the regenerated OSL. Implicitly, this study implies a caution on the use of palaeodoses obtained from single grains as such a correction is not possible in the currently used automated single grain OSL measurement systems. The only way now on will be to analyze aliquots with only a grain on them.
\end{abstract}

Keywords: SAR, NSC-SAR, OSL, Quartz, Optical dating.

Corresponding author: A. K. Singhvi

e-mail: singhvi@prl.res.in

ISSN 1897-1695 (online), 1733-8387 (print)

(C) 2011 Silesian University of Technology, Gliwice, Poland.

All rights reserved. 


\section{INTRODUCTION}

\section{The SAR protocol}

In quartz based optical dating, increasing use of single aliquot regeneration protocol for the estimation of equivalent dose $\left(D_{e}\right)$ is seen. Since the first report by Murray (1996), the method has been refined and Wintle and Murray (2006) summarize the current status of the SAR procedure. Single aliquot procedures were initially based on additive dose techniques similar to those first tested on feldspars (Duller, 1991; 1995; 1996). However for quartz, the focus of single aliquot studies shifted to regeneration techniques that involved measurement of natural OSL and regeneration of the OSL signal for the same aliquot using laboratory irradiation (Murray and Roberts, 1998; Murray and Mejdahl, 1999; Murray and Wintle, 2000). Such regeneration techniques assume that any changes in sensitivity during preheating-optical stimulationirradiation cycles can be monitored and corrected by evaluating either $\mathrm{OSL}$ or $110^{\circ} \mathrm{C} \mathrm{TL}$ responses to test doses administered following each preheat and optical stimulation cycle (Murray and Wintle, 2000). The attractiveness of the SAR protocol for the evaluation of $D_{e}$ lies in obtaining high precision $(<5 \%)$ in $D_{e}$ estimates by using large number of aliquots and in isolating the most bleached fraction. While on some occasions the SAR ages have been in reasonable agreement with independent age controls (e. g., Hansen et al., 1999; Murray and Mejdahl, 1999; Strickertsson and Murray, 1999), there have also been instances of samples with anomalously high natural OSL intensity that lies significantly beyond the saturation intensity of the regenerated luminescence vs. dose growth curve. Such instances provide indication that the natural OSL and the regeneration curves are not measured with the same OSL sensitivity.

Murray and Wintle (2000) outlined the basic SAR protocol for $D_{e}$ estimation. In this, the $D_{e}$ is calculated for each aliquot by repeated regenerative procedure involving the measurement of the natural OSL $\left(L_{0}\right)$ (cycle $n=0$, irradiation $=0 \mathrm{~Gy}$ ) by exposing the aliquot to an optical stimulation preceded by a pre-heat (Fig. 1). The efficacy of the SAR procedure is generally not influenced by the heating for short duration $(10-60 \mathrm{~s})$ pre-heat treatment over a temperature range $160-300^{\circ} \mathrm{C}$ (Murray and Wintle, 2000). The OSL signal is subsequently regenerated by a series of irradiation $\left(D_{n}\right)$-preheat-optical stimulation $\left(L_{n}\right)$ cycles (typically $n=5$ ). Three additional steps are incorporated to monitor and correct for unaccounted changes in the luminescence sensitivity of an aliquot during preheat and read out cycles. These involve the addition of a small (e.g. few Gy) test dose, a cut heat TL readout to $160^{\circ} \mathrm{C}$, and an optical stimulation to detect the OSL resulting from the test dose $\left(T_{n}\right)$. The corrected OSL signal (via low temperature TL or OSL response to the test dose) is given by,

$$
L_{n(\text { corr } .)}=\frac{L_{n}}{T_{n}}
$$

A background intensity is subtracted from the natural $\left(L_{0}\right)$, regenerated $\left(L_{n}\right)$, and test dose response $\left(T_{n}\right)$ signals are estimated as time-averaged OSL intensity following prolonged ( $>60 \mathrm{~s}$ ) optical stimulation. More recently, an earlier interval (immediately after the fast component) is used to minimize the interference of medium and slow components of quartz and ensure the use of only the fast component (Singhvi and Lang, 1998; Murari, 2008). The background and sensitivity corrected OSL intensities, are plotted as a function of laboratory beta dose to construct a regenerated growth curve, from which the $D_{e}$ values are estimated by interpolating the intensity of natural signal on the regenerated growth curve. In the SAR measurements, two additional tests are carried out (Murray and Wintle, 2000). The first test is the repetition of one of the regeneration doses at the end of growth curve construction. The ratio of sensitivity corrected OSL intensity for the two measurements provides a measure of appropriateness of the sensitivity correction (the 'recycling ratio'). The second test involves a pre-heat without giving any dose, followed by OSL measurement $\left(L_{\text {recup }}\right)$, and test dose irradiation (and a corresponding pre-heating and optical stimulation $\left(T_{\text {recup }}\right)$. This test measures the degree of thermal transfer occurring during SAR cycles.

\section{Sensitivity changes during the readout of natural OSL}

A critical assumption in the SAR procedure is that any change in the luminescence sensitivity of the sample

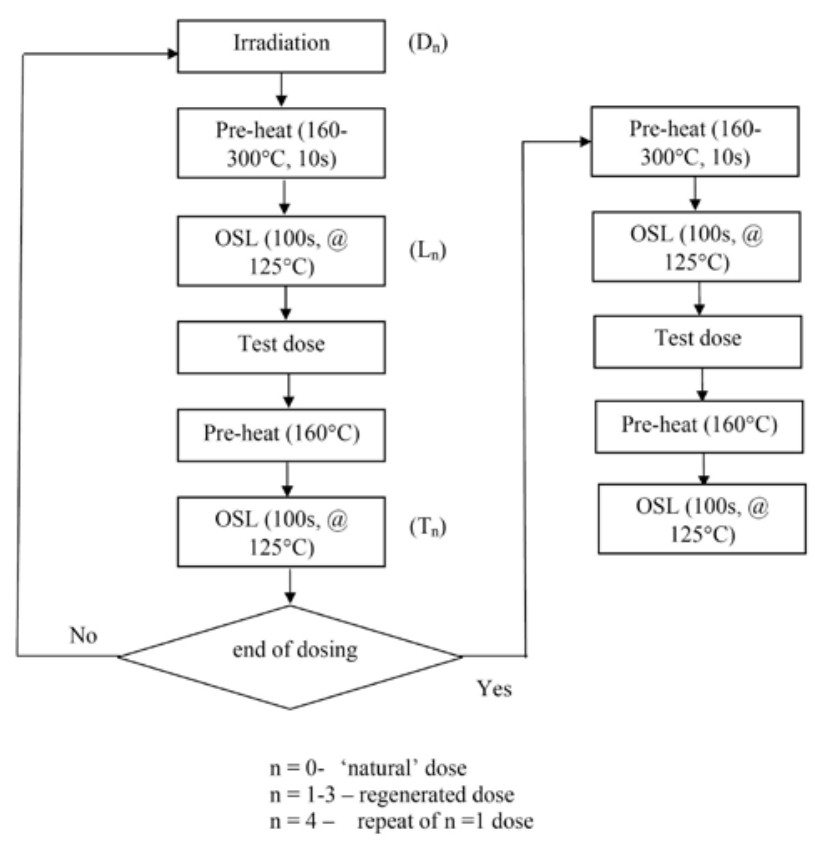

Fig. 1. SAR protocol suggested by Murray and Wintle, 2000. 
can be corrected using test dose OSL/TL. Although, data indicates that incremental OSL $/ 110^{\circ} \mathrm{C}$ TL responses to test doses measured subsequent to regenerative cycles can be considered as sufficient to quantify sensitivity changes during construction of the regenerated growth curve. It is however assumed that preheat and the OSL measurement of the natural OSL signal do not alter the luminescence sensitivity. However, we observed significant sensitivity changes during the measurement of natural signal. Hence, there is need to fold in this change in the SAR protocol for a reliable $\mathrm{D}_{\mathrm{e}}$ evaluation.

Based on $110^{\circ} \mathrm{C}$ TL and OSL sensitivity correlations, previous studies have described changes in the natural OSL sensitivity during pre-heating and optical stimulation of natural samples (Stokes, 1994a; b). This contribution also examined the effects of combining repeated irradiation and OSL measurement on changes in sensitivity via the use of, $110^{\circ} \mathrm{C}$ TL glowpeak. The results in the present study, suggested that $110^{\circ} \mathrm{C}$ TL or OSL sensitivity measured subsequent to preheat and optical stimulation of natural signal changes and the change occurs both during preheat and OSL read out. Hence, OSL sensitivity of sample as received is different from that after the readout of the natural OSL. In a SAR protocol, the $110^{\circ} \mathrm{C}$ TL or OSL measurements do track the sensitivity after the measurement of the natural OSL. Consequently for the samples where the sensitivity changes during the preheat and natural OSL readout, the application of the standard SAR procedure as used now, although may provide high precision palaeodoses, yet these could be systematically inaccurate (higher or lower).

We therefore suggest a modified NSC-SAR procedure that incorporates correcting the sensitivity changes during the read out and preheat of natural OSL. This procedure directly monitors sensitivity changes in the 'natural' signal by $110^{\circ} \mathrm{C}$ TL measurements, analogous to Stokes (1994b). The modified SAR procedure invariably reduces the scatter in the palaeodose distribution suggesting that some of the dispersion in the palaeodose arises due to sensitivity changes and not due to poor bleaching or the heterogeneity of radiation field (Mayya et al. 2006).

\section{THE SAMPLES}

Samples used in this study were collected from a variety of depositional environments ranging from aeolian sands (Thar Desert and Australia), fluvial environments from different provenances (flash floods, floodplains and slack water deposits) from river Alaknanda (Himalaya), Narmada (Central India), Namibia, Bangladesh and Vietnam, and from lacustrine environments (Thar Desert; Table 1). Use of conventional SAR protocol indicated the samples were well behaved with recycling ratios of $1.0 \pm 0.1$, and dose recovery within $\pm 10 \%$ of given dose.

\section{Sample preparation and measurements}

The samples were processed under subdued red light and were sequentially treated with $1 \mathrm{~N} \mathrm{HCl}$ (to remove carbonates) and $30 \% \mathrm{H}_{2} \mathrm{O}_{2}$ (to remove organic debris), and then sieved to separate the $90-150 \mu \mathrm{m}$ size grain fractions. Heavy minerals were removed using Frantz magnetic separator and by heavy density separation using sodium polytungstate (density $>2.72 \mathrm{~g} / \mathrm{cm}^{3}$ ). The samples were then etched with $40 \%$ hydrofluoric (HF) acid for $60-80$ minutes followed by $12 \mathrm{~N} \mathrm{HCl}$ for $30 \mathrm{~min}$ to extract pure quartz grains. After etching, the finer fraction was sieved out, as this fraction often comprised partially etched feldspar grain. The purity of the extracted grains was tested by examining their response to infrared stimulation (Stokes, 1992; Jain and Singhvi, 2001). Contaminated samples were re-etched with HF for $10 \mathrm{~min}$.

The measurements were conducted using various versions of RISØ TL/OSL readers fitted with blue diode arrays $\left(\lambda=470 \mathrm{~nm}\right.$, power $\left.=18 \mathrm{~mW} / \mathrm{cm}^{2}\right)$ and calibrated $\mathrm{Sr}^{90} / \mathrm{Y}^{90}$ beta radioactive sources. The detection optics comprised EMI 9235 QA photomultiplier and $7 \mathrm{~mm}$, Hoya U-340 glass filters. A preheat of $240^{\circ} \mathrm{C}$ for $10 \mathrm{~s}$ was used universally.

\section{MEASUREMENTS}

Sensitivity changes during repeated OSL readout and heating cycles was examined in detail. Both OSL only and preheat only cycles were first examined and these were followed by an examination of a combined OSL and preheat cycle (as in a standard SAR protocol).

\section{Sensitivity changes in OSL measurement cycle}

To monitor sensitivity changes during the repeated TL/OSL readout and irradiation, the intensity of $110^{\circ} \mathrm{C}$ TL peak corresponding to a small test dose was used at each stage. Fig. 2 gives the experimental protocol. In this a test dose (TD) of $\sim 30$ Gy was given after each step and the $110^{\circ} \mathrm{C}$ peak was recorded with a fixed interval between the irradiation and read out to ensure that signal loss due to thermal decay of $110^{\circ} \mathrm{C}$ was identical for all samples. Each read out was done till $200^{\circ} \mathrm{C}$, to ensure complete erasure of the peak. The sequence was repeated several times for a given regeneration dose and for OSL recording for $1000 \mathrm{~s}$. Fig 3a shows the variation of sensitivity with number of cycles. In this, the $110^{\circ} \mathrm{C}$ TL peak signal is normalized with respect to $110^{\circ} \mathrm{C} \mathrm{TL}$ peak $\left(\mathrm{TL}_{2}\right)$ following first TD. 
Table 1. Equivalent dose $\left(D_{e}\right)$ values before and after NCF correction and their percent change.

\begin{tabular}{|c|c|c|c|c|c|c|}
\hline \multirow{3}{*}{ Sample } & \multicolumn{4}{|c|}{$D_{e}(G y)$} & \multirow{2}{*}{\multicolumn{2}{|c|}{$\%$ change }} \\
\hline & \multicolumn{2}{|c|}{ Without correction } & \multicolumn{2}{|c|}{ After correction } & & \\
\hline & Least $10 \%$ & Mean & Least $10 \%$ & Mean & Least $10 \%$ & Mean \\
\hline $820 / 2$ & - & $17.2 \pm 1.1$ & - & $16.7 \pm 1.5$ & - & 3 \\
\hline $833 / 3$ & - & $19.8 \pm 1.2$ & - & $24.9 \pm 1.7$ & - & - \\
\hline $802 / 2$ & - & $6.2 \pm 0.4$ & - & $5.6 \pm 0.8$ & - & 9.7 \\
\hline $827 / 1$ & - & $13.4 \pm 1.1$ & - & $13.1 \pm 1.0$ & - & 2.2 \\
\hline BJ-1 & $9.7 \pm 1.8$ & $25.7 \pm 1.2$ & $7.8 \pm 1.6$ & $20.2 \pm 1.2$ & 20 & 21 \\
\hline BJ-2 & $9.4 \pm 0.5$ & $17.5 \pm 0.7$ & $8.0 \pm 1.0$ & $15.7 \pm 0.6$ & 16 & 10 \\
\hline$\overline{\mathrm{BJ}-5}$ & $14.1 \pm 1.0$ & $22.2 \pm 0.9$ & $13.7 \pm 0.7$ & $21.3 \pm 7.3$ & 3 & 4 \\
\hline$\overline{N B-1}$ & $34.0 \pm 0.2$ & $58 \pm 14$ & $31.6 \pm 1.8$ & $56.2 \pm 1.7$ & 7 & 3 \\
\hline$\overline{\mathrm{NB}-3}$ & $10.1 \pm 0.7$ & $23.0 \pm 2.0$ & $8.3 \pm 1.8$ & $19.1 \pm 1.0$ & 18 & 17 \\
\hline $9-4$ & $2.2 \pm 0.3$ & $2.8 \pm 1.5$ & $0.80 \pm 0.03$ & $1.20 \pm .0 .03$ & 63 & 57 \\
\hline$\overline{B N G-1}$ & $3.2 \pm 0.3$ & $5.6 \pm 1.6$ & $2.3 \pm 0.7$ & $5.3 \pm 1.7$ & 28 & 5 \\
\hline $\begin{array}{l}\mathrm{VPN}-5 \\
\end{array}$ & $12.1 \pm 0.7$ & $32.0 \pm 3.0$ & $10.2 \pm 1.8$ & $31.1 \pm 1.0$ & 15 & 3 \\
\hline $4-11-3$ & $0.10 \pm 0.01$ & $0.80 \pm 0.20$ & $0.10 \pm 0.01$ & $0.75 \pm 0.2$ & - & 6 \\
\hline$\overline{\text { OTS-1 }}$ & $19.4 \pm 5$ & $30.4 \pm 9.2$ & $18.2 \pm 0.6$ & $28.2 \pm 9.7$ & 7.8 & 6.6 \\
\hline$\overline{\text { OTS-2 }}$ & $3.4 \pm 0.5$ & $5.7 \pm 1.6$ & $2.9 \pm 0.4$ & $4.9 \pm 1.5$ & 16.3 & 17.2 \\
\hline$\overline{\text { OTS-3 }}$ & $18.2 \pm 0.5$ & $27.3 \pm 7.0$ & $13.4 \pm 0.4$ & $21.9 \pm 5.5$ & 24.7 & 35.8 \\
\hline OTS-4 & $8.5 \pm 2.8$ & $27 \pm 14$ & $6.2 \pm 2.0$ & $19.8 \pm 9.2$ & 36.4 & 37.1 \\
\hline OTS-5 & $1.7 \pm 0.1$ & $2.3 \pm 0.6$ & $1.4 \pm 0.1$ & $2.1 \pm 0.5$ & 9.5 & 21.4 \\
\hline RW-1 & $10.2 \pm 1.8$ & $24 \pm 12$ & $8.2 \pm 2.0$ & $21 \pm 13$ & 16.2 & 24.4 \\
\hline RW-2 & $3.3 \pm 0.5$ & $7.8 \pm 4.0$ & $2.7 \pm 0.5$ & $7.2 \pm 3.2$ & 8.3 & 22.2 \\
\hline RW-3 & $3.8 \pm 1.5$ & $12.1 \pm 5.1$ & $3.0 \pm 1.0$ & $9.2 \pm 4.0$ & 31.5 & 31.0 \\
\hline RW-4 & $14.0 \pm 3$ & $28 \pm 11$ & $11.0 \pm 2.0$ & $24 \pm 10$ & 19.2 & 26.4 \\
\hline MVW-10 & $1.0 \pm 0.2$ & $3.0 \pm 1.4$ & $0.8 \pm 0.2$ & $2.7 \pm 1.3$ & 11.1 & 12.5 \\
\hline MVW-11 & $28.6 \pm 4.1$ & $40.4 \pm 8.0$ & $22.6 \pm 3.5$ & $32.1 \pm 6.5$ & 26 & 26 \\
\hline MVW-13 & $10.3 \pm 1.6$ & $25 \pm 10$ & $8.4 \pm 1.1$ & $20.0 \pm 7.2$ & 25.5 & 22.6 \\
\hline MHK-07-01 & $29.7 \pm 0.5$ & $46.0 \pm 0.2$ & $25.7 \pm 0.6$ & $38.7 \pm 0.2$ & 13.6 & 16 \\
\hline MHK-07-02 & $26.8 \pm 0.2$ & $51.4 \pm 0.09$ & $23.9 \pm 0.2$ & $47.8 \pm 0.1$ & 10.9 & 7 \\
\hline MHK-07-03 & $47.7 \pm 0.5$ & $72.5 \pm 0.2$ & $41.6 \pm 0.8$ & $54.3 \pm 0.4$ & 12.7 & 25.1 \\
\hline MHK-07-04 & $61.3 \pm 1.1$ & $86.9 \pm 0.4$ & $50.6 \pm 1.0$ & $76.1 \pm 0.5$ & 17.5 & 12.4 \\
\hline MHK-07-05 & $66.1 \pm 0.4$ & $80.3 \pm 0.2$ & $58.5 \pm 0.4$ & $69.7 \pm 0.2$ & 11.5 & 13.2 \\
\hline MHK-07-06 & $27.0 \pm 0.2$ & $35.7 \pm 0.1$ & $26.3 \pm 0.2$ & $32.1 \pm 0.1$ & 2.5 & 10.2 \\
\hline MHK-07-07 & $36.5 \pm 0.3$ & $43.1 \pm 0.1$ & $32.4 \pm 0.2$ & $36.9 \pm 0.1$ & 11.2 & 14.2 \\
\hline MHK-09-09 & $50.9 \pm 1.0$ & $57.6 \pm 0.6$ & $34.3 \pm 1.3$ & $41.3 \pm 0.7$ & 32.7 & 28.2 \\
\hline MHK-12-09 & $60.9 \pm 1.2$ & $69.4 \pm 0.8$ & $38.7 \pm 0.9$ & $43.7 \pm 0.5$ & 36.4 & 37 \\
\hline MHK-13-09 & $67.1 \pm 2.5$ & $82.2 \pm 1.4$ & $40.4 \pm 1.7$ & $50.3 \pm 0.8$ & 38.8 & 39.8 \\
\hline MHK-15-09 & $75.2 \pm 1.9$ & $85.7 \pm 1.2$ & $47.6 \pm 1.1$ & $51.0 \pm 0.8$ & 36.7 & 44.4 \\
\hline R16-TL3-OXF & $9.3 \pm 0.3$ & $13.1 \pm 0.2$ & $7.4 \pm 0.4$ & $10.5 \pm 0.2$ & 20.4 & 19.8 \\
\hline R16-TL6 & $20.2 \pm 0.5$ & $25.1 \pm 0.3$ & $14.9 \pm 0.7$ & $22.9 \pm 0.5$ & 26.2 & 8.8 \\
\hline R16-TL7 & $11.4 \pm 1.2$ & $17.9 \pm 0.6$ & $8.2 \pm 0.9$ & $12.9 \pm 0.5$ & 27.7 & 27.7 \\
\hline TRMT-T & $1.4 \pm 0.3$ & $3.3 \pm 0.2$ & $2.8 \pm 0.3$ & $4.2 \pm 0.2$ & 104.2 & 28 \\
\hline TRMT-B & $4.4 \pm 0.4$ & $9.0 \pm 0.3$ & $3.0 \pm 0.6$ & $8.9 \pm 0.3$ & 1 & 31.4 \\
\hline
\end{tabular}

It is seen that sensitivity changed with each step in a cyclic manner and overall the sensitivity increased. The change was aliquot dependent and the change between $\mathrm{TL}_{1-2}$ and $\mathrm{TL}_{1-3}$ ranged from 0.7 to 0.76 . In general, the sensitivity after an OSL readout was higher than that before OSL read out, suggesting possibility of phototransfer of charges from deeper traps to OSL traps (similar to that reported by Bailiff et al., 1977). The change in sensitivity during natural OSL measurement is seen (Fig. 3a). The sensitivity changes significantly from $T L_{2}$ to $\mathrm{TL}_{3}$ (up to 20\%). This indicates that the test dose OSL signal is recorded at sensitivity different from the natural
OSL signal and hence cannot be used for correcting sensitivity of natural OSL. However, the regeneration signal can be corrected using the TD OSL signal as shown by the measurement for cycle no. 3 onwards. The resulting growth curve will correspond to sensitivity different from that of a natural sensitivity. Therefore, interpolation of natural signal on regenerated curve constructed using a different sensitivity, leads to systematic errors and a correction is needed. 


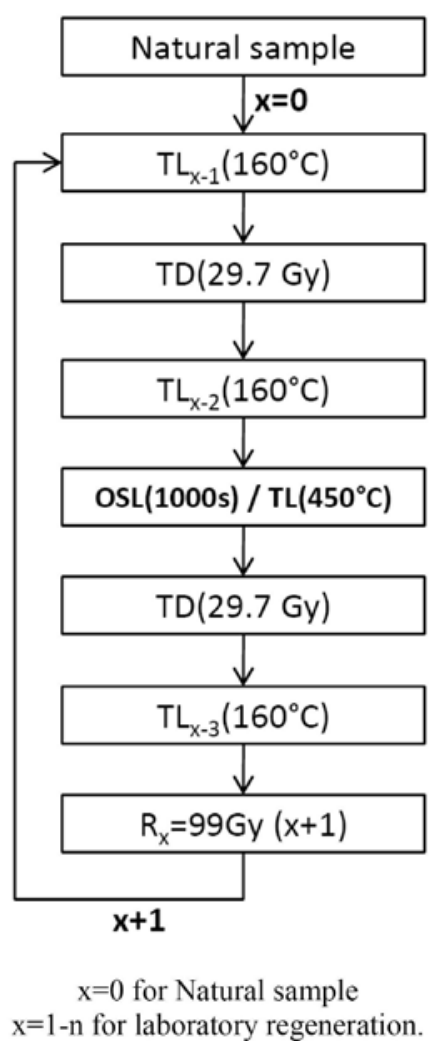

Fig. 2. Steps followed for the monitoring the sensitivity changes during repeated dosing, heating and $\mathrm{OSL}(1000 \mathrm{~s})$ or $\operatorname{TL}\left(450^{\circ} \mathrm{C}\right)$.

\section{Sensitivity changes during heating}

This measurement used a protocol similar to earlier protocol except that the OSL (1000 s) step was replaced with TL $\left(450^{\circ} \mathrm{C}\right)$ read out (Fig. 2). Fig. 3b shows the variation of sensitivity of $110^{\circ} \mathrm{C}$ TL peak with the repeated cycles of irradiation and TL measurements. The values in graph are normalized to $\mathrm{TL}_{2}$, which is the sensitivity of natural samples. Following inferences can be drawn from the Fig. 3b.

1) Similar to OSL measurements, the sensitivity changes are cyclic and show an overall increase.

2) The sensitivity before a TL $\left(450^{\circ} \mathrm{C}\right)$ readout is lower (Fig. 3b) than the sensitivity after TL $\left(450^{\circ} \mathrm{C}\right)$ suggesting thermal transfer during the $\mathrm{TL}\left(450^{\circ} \mathrm{C}\right)$ readout.

\section{Combined Preheat-OSL cycle}

Fig. 4 shows the modified SAR protocol that monitors the sensitivity changes during natural measurements. To monitor the sensitivity change during preheat and OSL measurement of natural (as received) signal, a test dose (TD1) was given before preheat $\left(240^{\circ} \mathrm{C}, 10 \mathrm{~s}\right)$ and corresponding $\mathrm{TL}_{\mathrm{a}}\left(\mathrm{RT}-200^{\circ} \mathrm{C}\right)$ is recorded. Similarly another test dose TD2 is given after the preheat $\left(240^{\circ} \mathrm{C}, 10 \mathrm{~s}\right)$ and

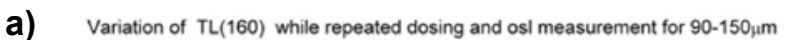

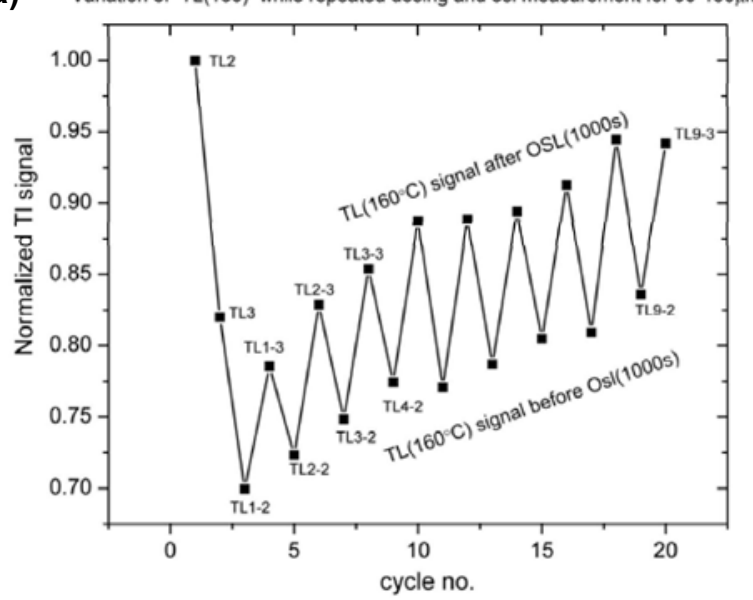

b) Variation of $\mathrm{TL}(160)$ while repeated dosing and $\mathrm{TI}$ measurement for $90-150 \mu \mathrm{m}$

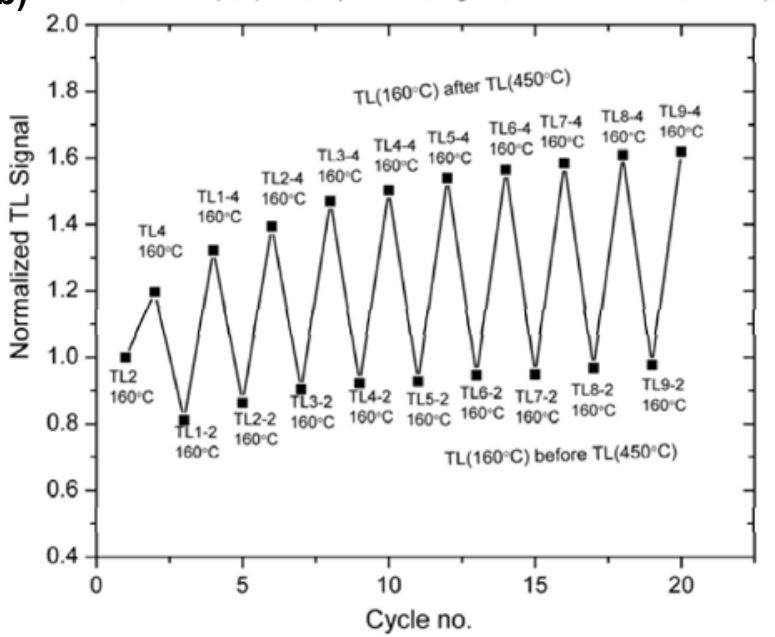

Fig. 3. a) sensitivity variation during repeated OSL(1000 s) measurement cycles, sensitivity is monitored by means of $110^{\circ} \mathrm{C} T L$ peak. The sensitivity is normalized with respect to $110^{\circ} \mathrm{C} T L$ peak for natural samples obtained by giving a TD, b) sensitivity variations during repeated $T L\left(450^{\circ} \mathrm{C}\right)$ measurement cycles.

corresponding $\mathrm{TL}_{\mathrm{b}}\left(\mathrm{RT}-200^{\circ} \mathrm{C}\right)$ was recorded. Natural OSL was then read and a test dose TD3 was given and $\mathrm{TL}_{3}\left(\mathrm{RT}-200^{\circ} \mathrm{C}\right.$ ) was recorded. The SAR protocol was then carried out. In view of the addition of beta dose prior to the read out of natural OSL, the dose (TD1+TD2) was subtracted from the palaeodose estimated by the NSCSAR protocol. To avoid complicating effects of either low temperature trap population during laboratory irradiation or photo-transfer to low $\left(<300^{\circ} \mathrm{C}\right)$ temperature traps during optical stimulation we included a thermal cleaning step of $200^{\circ} \mathrm{C} @ 2^{\circ} \mathrm{C} / \mathrm{s}$ prior to the test dose irradiation after OSL. The later part of the SAR protocol remained unchanged. The procedure permitted us to simultaneously construct a SAR growth curve and monitor sensitivity changes at each stage of its construction using integrated TL from $90-120^{\circ} \mathrm{C}$ considering its linear relation with OSL sensitivity (Murray et al., 1997; Murray 
and Roberts, 1998; Wintle and Murray, 1999; Murray and Wintle, 2000; Stokes, 1994a; b). This was examined in the present samples (Fig. 5). Table 1 shows the experimental results.

The experimental procedure in Fig. 4 permitted,

1) Estimation of the changes in the sensitivity of each aliquot due to pre-heating and optical stimulation during measurement of the 'natural' OSL signal

2) Examination of the net effect of change in natural sensitivity on $D_{e}$ via the 'natural correction factor' (NCF). This was used to correct $D_{e}$ for sensitivity changes during readout of the natural OSL.

3) Observation of sequential changes in sensitivity during measurement of both the natural and regenerated OSL, and

4) Assessment of the reproducibility of observed sensitivity changes by comparing results for aliquots from a number of samples.

\section{RESULTS}

\section{Changes in the $90-120^{\circ} \mathrm{C}$ TL sensitivity during the experimental procedure}

A wide range of behavior was observed in the samples that were examined (Fig. 6, Table 2). Differences between aliquots of same sample were seen. Thus, while for some aliquots no significant change in the sensitivity during the measurement of the natural OSL was seen, the
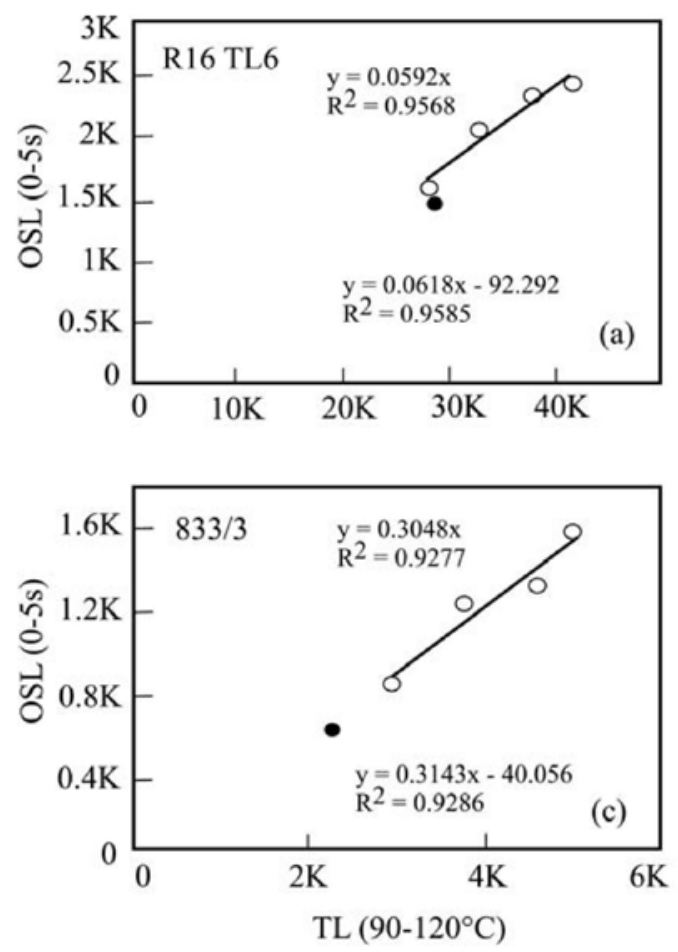

Fig. 5. Correlation between TL and OSL.

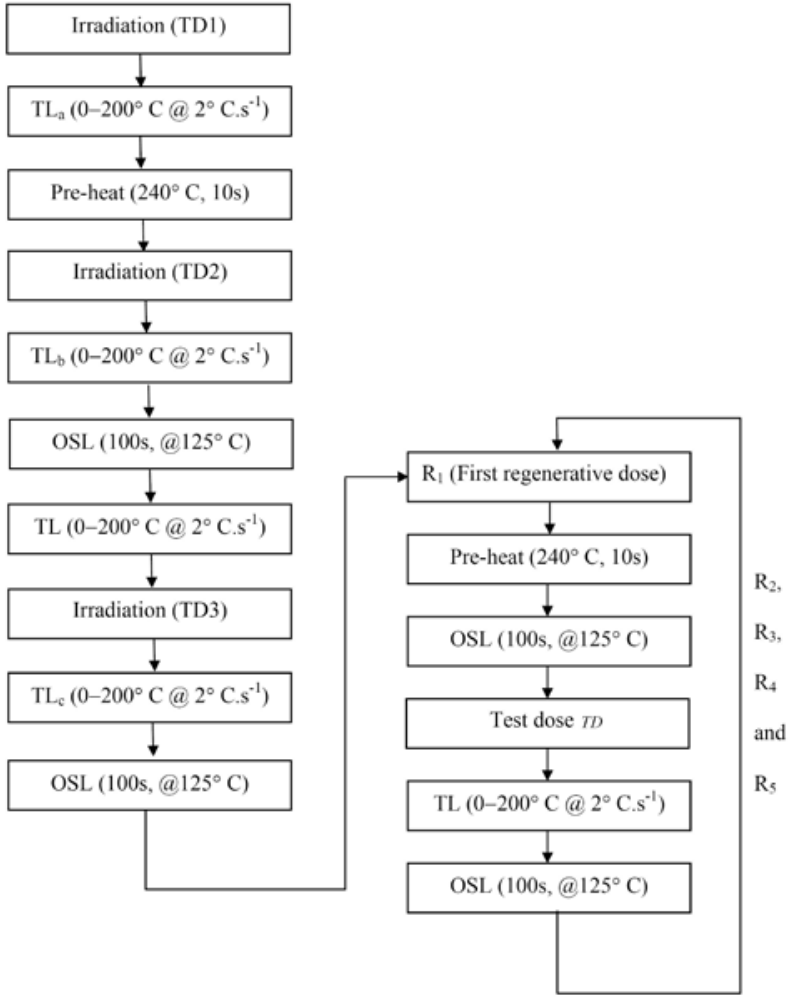

Fig. 4. Modified NSC-SAR protocol used to correct for the sensitivity changes occurring during the measurement of natural signal.
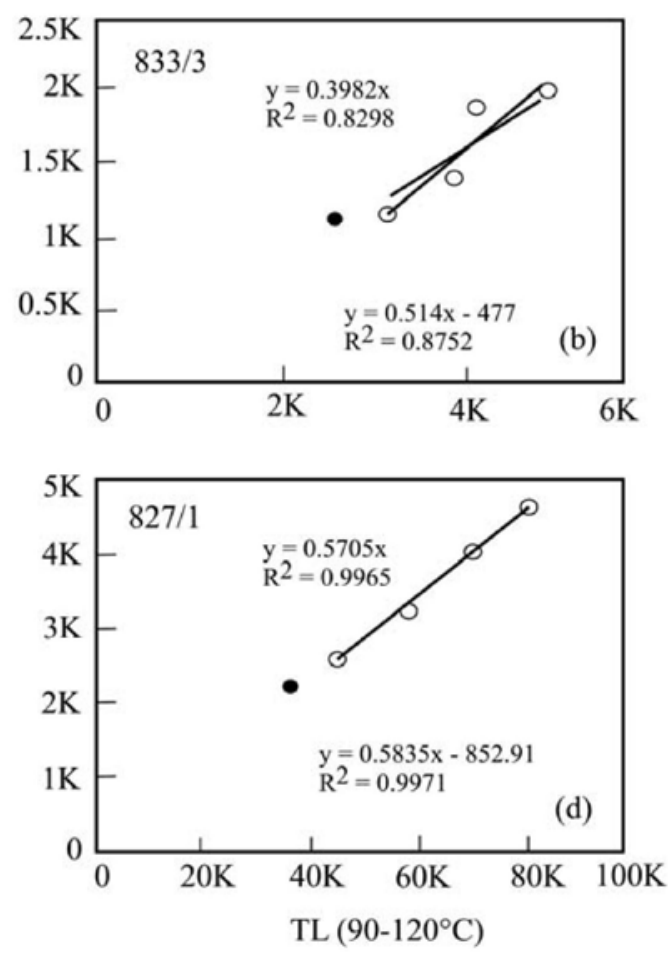
majority of aliquots exhibited a significant sensitivity change either during pre-heating and/or optical stimulation. Table 2 shows that the sensitivity can either increase or decrease during measurement of natural OSL and for majority of the samples, the ratio of the TD TL intensity after and before OSL (TD3/TD1) was $<1$, indicating that during the readout of natural OSL, generally sensitivity decreases. As in some of the cases there is no change in sensitivity during natural OSL measurement and ratio is $\sim 1$. There are few cases where OSL sensitivity during natural measurement increases.

Similar behavior for the sensitivity changes during the preheat measurements were observed and in this case also the variation could be either $<1,=1$ or $>1$. Thus we see that the combined effect results in either increase or decreases depending upon the extent of sensitivity variation in preheat and OSL readout. Such sensitivity changes have important implications for assumptions used in SAR protocol as discussed later. Sensitivity changes that occur during the regeneration cycles (steps 8-13, 15-20, 22-27, and 29-34) also exhibit considerable sample-to-sample and aliquot-to-aliquot variability (Fig. 6).

The observed contrast between the natural and regenerated sensitivity was further examined by comparing the relationship of the $90-120^{\circ} \mathrm{C}$ TL and OSL sensitivities for natural and regenerated signals (Fig. 5). The OSL and $90-120^{\circ} \mathrm{C}$ TL sensitivities following regenerative cycles exhibit statistically significant linear correlation with regression lines that pass close to the origin in most cases. While the relationship between OSL and the $90-120^{\circ} \mathrm{C}$ TL sensitivity in some cases were well defined by the same best fit lines (e.g. Figs. 5c, d), the majority of aliquots examined produced 'natural' OSL vs. TL sensitivity relationships that were not in agreement with the regeneration cycle-based best fit lines (e.g. Figs. 5a, b). As alluded to, in some cases the OSL sensitivity was in excess (e.g., Fig. 5b) while in other cases deficient (e.g. Fig. 5a). These trends closely match the trends of lower (below the best-fit line) and higher (above the best-fit line) $90-120^{\circ} \mathrm{C} \mathrm{TL}$ sensitivity in the course of measurement of the natural OSL (Table 2). The best-fit regression equations were used to derive a 'predicted' OSL sensitivity following measurement of the natural by solving the equation for each of the given values of $90-120^{\circ} \mathrm{C}$ TL sensitivity. The ratios of observed to predicted OSL sensitivities following natural OSL measurement are provided in Table 2. In most cases the ratio closely mimics the overall change in the $90-120^{\circ} \mathrm{C}$ TL sensitivity during measurement of the natural OSL.

The above observations suggest that in some cases the OSL (or TL) sensitivity measured following readout of the natural OSL may not be a realistic measure of the sensitivity of the natural signal. Therefore the use of a 'Natural Correction Factor' (NCF), which is the ratio of the $90-120^{\circ} \mathrm{C} \mathrm{TL}$ sensitivity obtained initially $\left(\mathrm{TL}_{\mathrm{a}}\right.$ for TD1) and after the natural OSL measurement $\left(\mathrm{TL}_{\mathrm{c}}\right.$ for TD3), becomes necessary (Fig. 4). Table 2, summarizes
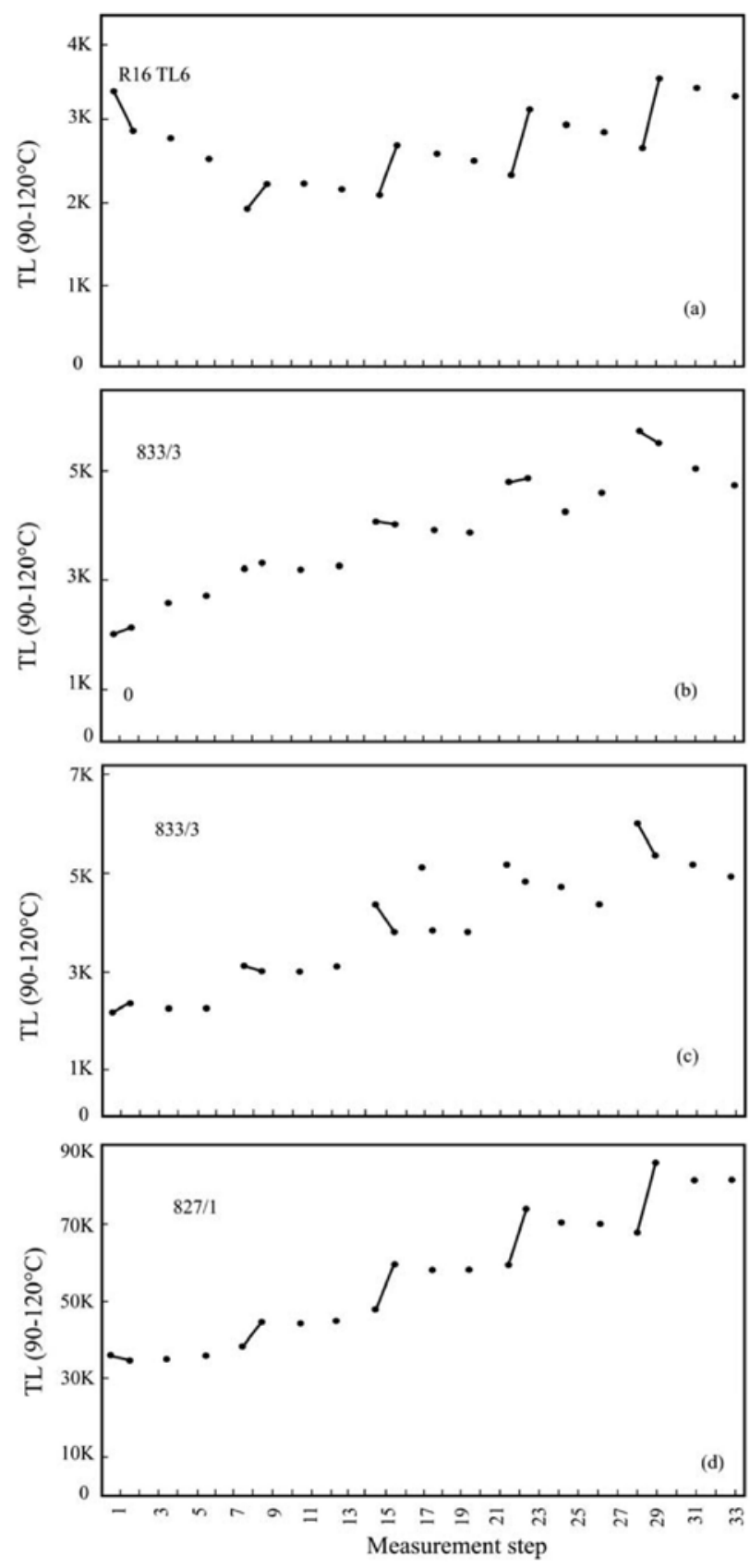

Fig. 6. Sensitivity variation during SAR measurement.

the sensitivity changes for a representative set of samples from diverse depositional environments

We propose that natural OSL signals are corrected by this factor, so that

$L_{n a t, \text { corr }}=\left(\frac{L_{\text {nat }}}{T_{\text {nat }}}\right) \times \frac{1}{\mathrm{NCF}}$,

where NCF is the ratio: 
Table 2. Variation of the preheat and OSL sensitivity factors and ratio of corresponding doses with and without use of correction factors.

\begin{tabular}{|c|c|c|c|c|c|c|c|c|}
\hline \multirow{2}{*}{ Sample } & \multirow{2}{*}{ Disc } & \multirow{2}{*}{ Post P.heat / Pre P.heat } & \multirow{2}{*}{ Post OSL / Pre OSL } & \multirow{2}{*}{$\begin{array}{l}\text { Overall } \\
\text { Change }\end{array}$} & \multirow{2}{*}{$\begin{array}{c}\text { Natural correction } \\
\text { factor }\end{array}$} & \multicolumn{3}{|c|}{ TL correction factor } \\
\hline & & & & & & $\mathrm{D}_{\mathrm{e}(\mathrm{corr})}$ & $\mathrm{D}_{\mathrm{e} \text { (uncorr) }}$ & $\mathrm{D}_{\mathrm{e}(\text { corr }) /} \mathrm{D}_{\mathrm{e} \text { (uncorr) }}$ \\
\hline \multirow{2}{*}{ R16 -TL6 } & 1 & $0.85 \pm 0.01$ & $0.97 \pm 0.01$ & $0.82 \pm 0.01$ & $1.22 \pm 0.01$ & $16.6 \pm 0.4$ & $22.7 \pm 0.4$ & $0.73 \pm 0.02$ \\
\hline & 2 & $0.80 \pm 0.01$ & $0.87 \pm 0.01$ & $0.70 \pm 0.01$ & $1.44 \pm 0.01$ & $10.5 \pm 0.3$ & $19.5 \pm 0.3$ & $0.54 \pm 0.02$ \\
\hline \multirow{2}{*}{$820 / 2$} & 1 & $1.02 \pm 0.02$ & $1.02 \pm 0.02$ & $1.02 \pm 0.02$ & $0.98 \pm 0.01$ & $18.1 \pm 0.7$ & $17.3 \pm 0.7$ & $1.05 \pm 0.06$ \\
\hline & 2 & $0.95 \pm 0.01$ & $0.97 \pm 0.01$ & $0.93 \pm 0.01$ & $1.08 \pm 0.01$ & $15.2 \pm 0.3$ & $17.2 \pm 0.3$ & $0.88 \pm 0.02$ \\
\hline \multirow{2}{*}{$833 / 3$} & 1 & $1.05 \pm 0.05$ & $1.21 \pm 0.05$ & $1.27 \pm 0.04$ & $0.79 \pm 0.02$ & $27.9 \pm 1.7$ & $19.2 \pm 1.5$ & $1.45 \pm 0.14$ \\
\hline & 2 & $1.08 \pm 0.05$ & $0.97 \pm 0.04$ & $1.05 \pm 0.03$ & $0.95 \pm 0.03$ & $20.5 \pm 1.4$ & $20.5 \pm 1.4$ & $1.07 \pm 0.10$ \\
\hline \multirow{2}{*}{$802 / 2$} & 1 & $0.99 \pm 0.01$ & $0.99 \pm 0.01$ & $0.97 \pm 0.01$ & $1.03 \pm 0.01$ & $5.0 \pm 0.1$ & $5.0 \pm 0.1$ & $0.92 \pm 0.03$ \\
\hline & 2 & $0.97 \pm 0.01$ & $0.99 \pm 0.01$ & $0.95 \pm 0.01$ & $1.05 \pm 0.01$ & $7.4 \pm 0.1$ & $7.4 \pm 0.1$ & $0.91 \pm 0.02$ \\
\hline \multirow{2}{*}{$827 / 1$} & 1 & $0.96 \pm 0.01$ & $1.01 \pm 0.01$ & $0.97 \pm 0.01$ & $1.03 \pm 0.01$ & $15.8 \pm 0.2$ & $15.8 \pm 0.2$ & $0.96 \pm 0.02$ \\
\hline & 2 & $1.00 \pm 0.01$ & $1.01 \pm 0.01$ & $1.01 \pm 0.01$ & $0.99 \pm 0.01$ & $11.0 \pm 0.2$ & $11.0 \pm 0.2$ & $1.02 \pm 0.02$ \\
\hline \multirow{2}{*}{ BJ-1 } & 1 & $0.97 \pm 0.01$ & $1.10 \pm 0.05$ & $1.07 \pm 0.04$ & $1.10 \pm 0.02$ & $5.2 \pm 0.2$ & $6.7 \pm 0.3$ & $0.78 \pm 0.04$ \\
\hline & 2 & $0.81 \pm 0.01$ & $1.02 \pm 0.02$ & $0.83 \pm 0.02$ & $1.10 \pm 0.02$ & $5.3 \pm 0.2$ & $6.7 \pm 0.4$ & $0.78 \pm 0.05$ \\
\hline \multirow[b]{2}{*}{ BJ-2 } & 1 & $0.97 \pm 0.01$ & $1.10 \pm 0.05$ & $1.00 \pm 0.04$ & $1.10 \pm 0.02$ & $12.9 \pm 1.1$ & $15.7 \pm 1.7$ & $0.82 \pm 0.01$ \\
\hline & 2 & $0.81 \pm 0.01$ & $1.02 \pm 0.02$ & $0.83 \pm 0.02$ & $1.12 \pm 0.02$ & $16.7 \pm 0.9$ & $17.6 \pm 1.2$ & $0.95 \pm 0.01$ \\
\hline \multirow{2}{*}{ BJ-5 } & 1 & $0.92 \pm 0.01$ & $0.97 \pm 0.02$ & $0.90 \pm 0.02$ & $1.10 \pm 0.02$ & $13.0 \pm 0.8$ & $13.0 \pm 1.7$ & $1.00 \pm 0.01$ \\
\hline & 2 & $0.94 \pm 0.01$ & $1.06 \pm 0.05$ & $1.00 \pm 0.04$ & $1.10 \pm 0.02$ & $14.0 \pm 0.8$ & $13.8 \pm 1.1$ & $1.01 \pm 0.01$ \\
\hline & 1 & $0.96 \pm 0.01$ & $0.94 \pm 0.01$ & $0.90 \pm 0.02$ & $0.97 \pm 0.01$ & $25.4 \pm 2.1$ & $28.6 \pm 2.7$ & $0.89 \pm 0.11$ \\
\hline NB-1 & 2 & $0.86 \pm 0.01$ & $0.88 \pm 0.01$ & $0.76 \pm 0.01$ & $1.01 \pm 0.01$ & $27.4 \pm 2.2$ & $31.5 \pm 2.8$ & $0.87 \pm 0.10$ \\
\hline & 1 & $0.97 \pm 0.01$ & $0.98 \pm 0.01$ & $0.95 \pm 0.01$ & $1.10 \pm 0.01$ & $4.8 \pm 1.1$ & $5.4 \pm 1.3$ & $0.89 \pm 0.07$ \\
\hline NB-3 & 2 & $1.00 \pm 0.01$ & $0.96 \pm 0.01$ & $0.96 \pm 0.01$ & $1.10 \pm 0.01$ & $7.8 \pm 1.2$ & $8.1 \pm 1.6$ & $0.96 \pm 0.03$ \\
\hline & $\frac{2}{1}$ & $0.98 \pm 0.01$ & $0.99 \pm 0.01$ & $0.97 \pm 0.01$ & $1.01 \pm 0.01$ & $0.10 \pm 0.01$ & $0.14 \pm 0.01$ & $0.71 \pm 0.09$ \\
\hline $4-11-3$ & 2 & $1.05 \pm 0.05$ & $0.99 \pm 0.01$ & $1.03 \pm 0.04$ & $0.95 \pm 0.01$ & $0.10 \pm 0.01$ & $0.13 . \pm 0.01$ & $0.77 \pm 0.10$ \\
\hline & 1 & $0.96 \pm 0.01$ & $1.16 \pm 0.05$ & $1.11 \pm 0.05$ & $1.16 \pm 0.04$ & $0.80 \pm 0.03$ & $2.1 \pm 0.02$ & $0.38 \pm 0.01$ \\
\hline $9-4$ & 2 & $1.05 \pm 0.05$ & $1.05 \pm 0.01$ & $1.10 \pm 0.05$ & $1.12 \pm 0.05$ & $0.76 \pm 0.02$ & $1.8 . \pm 0.02$ & $0.42 \pm 0.01$ \\
\hline & 1 & $0.92 \pm 0.01$ & $0.99 \pm 0.01$ & $0.91 \pm 0.01$ & $0.92 \pm 0.01$ & & & \\
\hline VPN-5 & 2 & $0.89 \pm 0.01$ & $0.96 \pm 0.01$ & $0.85 \pm 0.01$ & $0.90 \pm 0.01$ & & & \\
\hline & 1 & $0.77 \pm 0.01$ & $1.55 \pm 0.06$ & $1.20 \pm 0.05$ & $0.80 \pm 0.01$ & $0.80 \pm 0.03$ & $2.1 \pm 0.02$ & $0.38 \pm 0.01$ \\
\hline BNG-1 & 2 & $0.76 \pm 0.01$ & $1.61 \pm 0.01$ & $1.20 \pm 0.01$ & $0.76 \pm 0.01$ & $0.76 \pm 0.02$ & $1.8 . \pm 0.02$ & $0.42 \pm 0.01$ \\
\hline & 1 & $0.61 \pm 0.01$ & $0.97 \pm 0.02$ & $0.60 \pm 0.01$ & $1.06 \pm 0.02$ & $33.0 \pm 4.4$ & $35.0 \pm 4.7$ & $0.94 \pm 0.01$ \\
\hline MVV-11 & 2 & $0.62 \pm 0.01$ & $1.07 \pm 0.02$ & $0.66 \pm 0.01$ & $1.19 \pm 0.05$ & $27.9 \pm 2.6$ & $33.2 . \pm 3.1$ & $0.84 \pm 0.01$ \\
\hline & 1 & $1.18 \pm 0.05$ & $0.88 \pm 0.01$ & $1.03 \pm 0.05$ & $1.02 \pm 0.02$ & $13.8 \pm 0.9$ & $15.4 \pm 1.8$ & $0.98 \pm 0.01$ \\
\hline IVIVVV-13 & 2 & $1.01 \pm 0.01$ & $0.83 \pm 0.01$ & $0.83 \pm 0.01$ & $1.17 \pm 0.05$ & $36.9 \pm 1.4$ & 43.5. \pm 1.6 & $0.86 \pm 0.01$ \\
\hline & 1 & $0.67 \pm 0.01$ & $0.70 \pm 0.01$ & $0.50 \pm 0.01$ & $1.29 \pm 0.04$ & $25.7 \pm 1.1$ & $29.8 \pm 1.2$ & $0.86 \pm 0.01$ \\
\hline RW-1 & 2 & $0.79 \pm 0.01$ & $0.73 \pm 0.01$ & $0.60 \pm 0.01$ & $1.27 \pm 0.05$ & $16.3 \pm 0.7$ & $21.1 \pm 0.9$ & $0.77 \pm 0.01$ \\
\hline & 1 & $1.22 \pm 0.01$ & $0.68 \pm 0.01$ & $0.83 \pm 0.01$ & $1.22 \pm 0.03$ & $19.8 \pm 1.9$ & $24.2 \pm 2.3$ & $0.82 \pm 0.01$ \\
\hline RW-4 & 2 & $1.13 \pm 0.01$ & $0.55 \pm 0.01$ & $0.62 \pm 0.01$ & $1.26 \pm 0.05$ & $16.2 \pm 1.0$ & $20.4 \pm 1.3$ & $0.79 \pm 0.01$ \\
\hline & 1 & $0.89 \pm 0.01$ & $0.63 \pm 0.01$ & $0.56 \pm 0.01$ & $1.08 \pm 0.03$ & $21.4 \pm 1.0$ & $30.5 \pm 1.4$ & $0.70 \pm 0.01$ \\
\hline OIS-1 & 2 & $0.88 \pm 0.01$ & $0.58 \pm 0.01$ & $0.51 \pm 0.01$ & $0.97 \pm 0.01$ & $22.4 \pm 1.2$ & $25.5 \pm 1.4$ & $0.88 \pm 0.01$ \\
\hline & 1 & $0.98 \pm 0.01$ & $0.89 \pm 0.01$ & $0.87 \pm 0.01$ & $1.12 \pm 0.05$ & $3.2 \pm 0.2$ & $3.6 \pm 0.3$ & $0.89 \pm 0.03$ \\
\hline UIS-5 & 2 & $0.98 \pm 0.01$ & $0.94 \pm 0.01$ & $0.92 \pm 0.01$ & $1.11 \pm 0.04$ & $2.1 \pm 0.2$ & $2.3 \pm 0.2$ & $0.91 \pm 0.06$ \\
\hline & 1 & $0.84 \pm 0.01$ & $0.81 \pm 0.01$ & $0.69 \pm 0.01$ & $0.676 \pm 0.007$ & $1.48 \pm 0.01$ & $51.1 \pm 1.1$ & $0.66 \pm 0.04$ \\
\hline MHK-07-01 & 2 & $0.85 \pm 0.01$ & $0.94 \pm 0.01$ & $0.80 \pm 0.01$ & $0.800 \pm 0.009$ & $1.25 \pm 0.01$ & $37.6 \pm 1.3$ & $0.90 \pm 0.05$ \\
\hline & 1 & $0.850 \pm 0.003$ & $0.918 \pm 0.003$ & $0.78 \pm 0.001$ & $0.781 \pm 0.003$ & $1.281 \pm 0.005$ & $62.2 \pm 0.8$ & $0.90 \pm 0.02$ \\
\hline MHK-0/-02 & 2 & $0.842 \pm 0.003$ & $0.934 \pm 0.003$ & $0.80 \pm 0.001$ & $0.787 \pm 0.003$ & $1.271 \pm 0.005$ & $76.9 \pm 1.3$ & $0.85 \pm 0.02$ \\
\hline & 1 & $0.70 \pm 0.01$ & $0.89 \pm 0.01$ & $0.62 \pm 0.01$ & $0.620 \pm 0.005$ & $1.61 \pm 0.01$ & $91.8 \pm 1.9$ & $0.75 \pm 0.04$ \\
\hline $\mathrm{MHK}-0 /-03$ & 2 & $0.70 \pm 0.01$ & $0.95 \pm 0.01$ & $0.67 \pm 0.01$ & $0.665 \pm 0.005$ & $1.50 \pm 0.01$ & $56.8 \pm 1.3$ & $0.85 \pm 0.04$ \\
\hline & 1 & $0.88 \pm 0.01$ & $0.94 \pm 0.01$ & $0.83 \pm 0.01$ & $0.834 \pm 0.006$ & $1.20 \pm 0.01$ & $81.8 \pm 1.6$ & $0.91 \pm 0.04$ \\
\hline MHK-07-04 & 2 & $0.86 \pm 0.01$ & $0.96 \pm 0.01$ & $0.83 \pm 0.01$ & $0.824 \pm 0.008$ & $1.21 \pm 0.01$ & $67.6 \pm 2.0$ & $0.96 \pm 0.05$ \\
\hline & 1 & $0.858 \pm 0.004$ & $0.870 \pm 0.005$ & $0.75 \pm 0.004$ & $0.746 \pm 0.004$ & $1.34 \pm 0.01$ & $97.0 \pm 1.2$ & $0.77 \pm 0.02$ \\
\hline MHK-07-05 & 2 & $0.830 \pm 0.004$ & $0.886 \pm 0.005$ & $0.74 \pm 0.004$ & $0.735 \pm 0.004$ & $1.36 \pm 0.01$ & $95.7 \pm 1.4$ & $0.80 \pm 0.02$ \\
\hline & 1 & $0.829 \pm 0.004$ & $0.913 \pm 0.005$ & $0.76 \pm 0.004$ & $0.757 \pm 0.004$ & $1.32 \pm 0.01$ & $35.9 \pm 0.2$ & $0.87 \pm 0.01$ \\
\hline MHK-0/-06 & 2 & $0.807 \pm 0.004$ & $0.94 \pm 0.01$ & $0.76 \pm 0.002$ & $0.757 \pm 0.004$ & $1.32 \pm 0.01$ & $33.5 \pm 0.4$ & $0.90 \pm 0.02$ \\
\hline & 1 & $0.784 \pm 0.004$ & $0.894 \pm 0.005$ & $0.70 \pm 0.004$ & $0.702 \pm 0.004$ & $1.43 \pm 0.01$ & $42.2 \pm 0.4$ & $0.86 \pm 0.01$ \\
\hline KK-07-07 & 2 & $0.773 \pm 0.003$ & $0.933 \pm 0.004$ & $0.72 \pm 0.002$ & $0.721 \pm 0.003$ & $1.39 \pm 0.01$ & $49.1 \pm 0.5$ & $0.88 \pm 0.02$ \\
\hline & 1 & $0.962 \pm 0.005$ & $0.879 \pm 0.004$ & $0.845 \pm 0.004$ & $0.845 \pm 0.004$ & $1.18 \pm 0.01$ & $49.8 \pm 3.6$ & $0.70 \pm 0.02$ \\
\hline MHK-09-09 & 2 & $0.959 \pm 0.004$ & $0.906 \pm 0.004$ & $0.869 \pm 0.004$ & $0.869 \pm 0.004$ & $1.15 \pm 0.01$ & $51.6 \pm 3.8$ & $0.74 \pm 0.02$ \\
\hline & 1 & $0.903 \pm 0.004$ & $0.882 \pm 0.004$ & $0.797 \pm 0.003$ & $0.797 \pm 0.003$ & $1.26 \pm 0.01$ & $79.2 \pm 8.9$ & $0.54 \pm 0.02$ \\
\hline IK-12-09 & 2 & $0.851 \pm 0.004$ & $0.852 \pm 0.005$ & $0.725 \pm 0.004$ & $0.725 \pm 0.004$ & $1.38 \pm 0.01$ & $74.9 \pm 7.1$ & $0.53 \pm 0.02$ \\
\hline
\end{tabular}


Table 2. Continuation.

\begin{tabular}{|c|c|c|c|c|c|c|c|c|}
\hline \multirow{2}{*}{ Sample } & \multirow{2}{*}{ Disc } & \multirow{2}{*}{ Post P.heat / Pre P.heat } & \multirow{2}{*}{ Post OSL / Pre OSL } & \multirow{2}{*}{$\begin{array}{l}\text { Overall } \\
\text { Change }\end{array}$} & \multirow{2}{*}{$\begin{array}{c}\text { Natural correction } \\
\text { factor }\end{array}$} & \multicolumn{3}{|c|}{ TL correction factor } \\
\hline & & & & & & $\mathrm{D}_{\mathrm{e}(\mathrm{corr})}$ & $\mathrm{D}_{\text {e(uncorr) }}$ & $\mathrm{D}_{\mathrm{e}(\text { corr }) /} \mathrm{D}_{\mathrm{e} \text { (uncorr) }}$ \\
\hline \multirow{2}{*}{ MHK-13-09 } & 1 & $0.927 \pm 0.005$ & $0.870 \pm 0.005$ & $0.807 \pm 0.004$ & $0.807 \pm 0.004$ & $1.24 \pm 0.01$ & $102.4 \pm 13.3$ & $0.52 \pm 0.01$ \\
\hline & 2 & $0.92 \pm 0.01$ & $0.85 \pm 0.01$ & $0.776 \pm 0.001$ & $0.776 \pm 0.005$ & $1.29 \pm 0.01$ & $107.0 \pm 14.6$ & $0.47 \pm 0.02$ \\
\hline \multirow{2}{*}{ MHK-15-09 } & 1 & $0.87 \pm 0.01$ & $0.89 \pm 0.01$ & $0.776 \pm 0.001$ & $0.776 \pm 0.005$ & $1.29 \pm 0.01$ & $86.7 \pm 7.1$ & $0.58 \pm 0.01$ \\
\hline & 2 & $0.89 \pm 0.01$ & $0.90 \pm 0.01$ & $0.801 \pm 0.001$ & $0.796 \pm 0.005$ & $1.26 \pm 0.01$ & $107.6 \pm 8.2$ & $0.60 \pm 0.01$ \\
\hline \multirow{4}{*}{$\begin{array}{l}\text { R16-TL3- } \\
\text { OXF } \\
\text { R16-TL7 }\end{array}$} & 1 & $1.065 \pm 0.002$ & $0.822 \pm 0.002$ & $0.87 \pm 0.002$ & $0.876 \pm 0.002$ & $1.142 \pm 0.003$ & $7.1 \pm 1.0$ & $0.55 \pm 0.05$ \\
\hline & 2 & $1.120 \pm 0.003$ & $0.824 \pm 0.002$ & $0.92 \pm 0.002$ & $0.923 \pm 0.003$ & $1.084 \pm 0.003$ & $15.1 \pm 1.4$ & $0.82 \pm 0.01$ \\
\hline & 1 & $1.02 \pm 0.01$ & $0.88 \pm 0.01$ & $0.90 \pm 0.001$ & $0.905 \pm 0.007$ & $1.11 \pm 0.01$ & $50 \pm 16$ & $0.71 \pm 0.07$ \\
\hline & 2 & $1.08 \pm 0.01$ & $0.86 \pm 0.01$ & $0.93 \pm 0.001$ & $0.929 \pm 0.008$ & $1.08 \pm 0.01$ & $26.0 \pm 4.0$ & $0.86 \pm 0.09$ \\
\hline \multirow[t]{2}{*}{ TRMT-T } & 1 & $1.225 \pm 0.002$ & $0.864 \pm 0.002$ & $1.06 \pm 0.002$ & $1.058 \pm 0.002$ & $0.945 \pm 0.002$ & $11.3 \pm 1.5$ & $1.2 \pm 0.2$ \\
\hline & 2 & $1.239 \pm 0.003$ & $0.881 \pm 0.002$ & $1.09 \pm 0.002$ & $1.092 \pm 0.002$ & $0.916 \pm 0.002$ & $5.6 \pm 1.2$ & $1.8 \pm 0.3$ \\
\hline \multirow[t]{2}{*}{ TRMT-B } & 1 & $1.121 \pm 0.003$ & $0.942 \pm 0.003$ & $1.06 \pm 0.003$ & $1.057 \pm 0.003$ & $0.946 \pm 0.003$ & $8.6 \pm 1.4$ & $1.24 \pm 0.2$ \\
\hline & 2 & $1.054 \pm 0.003$ & $0.901 \pm 0.003$ & $0.94 \pm 0.003$ & $0.950 \pm 0.003$ & $1.052 \pm 0.004$ & $14.0 \pm 1.7$ & $0.86 \pm 0.02$ \\
\hline
\end{tabular}

$\mathrm{NCF}=\frac{T L_{1}}{T L_{3}}$,

under the proviso that the test doses are the same.

This procedure can be easily folded in, with the standard SAR procedure of Murray and Wintle (2000) and adequately corrects for changes that have occurred during the SAR regeneration cycles. A suggestion here is to use test doses of $>10 \mathrm{~Gy}$ to minimize differences in the supralinearity of individual grains. The approach suggested above is based on the observations of good correlation between the $90-120^{\circ} \mathrm{C}$ TL and OSL during regeneration cycles (Fig. 5). Fig. 7 gives a plot of the ratios of $D_{e}$ with and without correction factors, which shows that with a few exceptions, most samples have SAR ages that have systematic offset. While it is difficult to compare these results against robust ages (if there are any!), the fact that in all cases the scatter in paleodoses reduced irrespective of the diverse variability in individual aliquots, suggests the efficacy of the correction procedure.

\section{DISCUSSION}

The development of SAR based $D_{e}$ determination procedure has been one of the most exciting research initiatives in luminescence dating. However, we had some concerns over the lack of measurement of the natural sensitivity prior to measurement of the natural OSL, and considered this to be a potential 'Achilles heel' for the SAR procedures. The present study affirms that significant sensitivity changes during readout of the natural OSL occur for most samples. The change is variable in magnitude and direction from one aliquot to the another aliquot and implicitly from grain to grain, given that only a few grains contribute to the OSL. We employed $90-120^{\circ} \mathrm{C}$ TL sensitivity as a surrogate for sensitivity change during the read out of natural OSL. Importantly, it was seen that these changes are dissimilar to those, which occur during regeneration measurements. In the absence of such a correction systematic errors in any $D_{e}$ estimate using conventional SAR are to be expected. This in itself may serve as a useful criterion to identify and /or reject potentially problematic samples.

The proposal is to employ a correction factor to correct for possible sensitivity change of the natural aliquot. This strategy effectively adjusts the sensitivity of the natural OSL measurement to match the linear OSL $90-120^{\circ} \mathrm{C}$ TL relationship observed during the regeneration cycles. Table 1 shows the data set comparing the $D_{e}$ estimated using of the natural correction factor $(N C F)$. These dose values are significantly different from estimates made using conventional SAR.

The latest version of the SAR protocol is termed the standard SAR (Murray and Wintle, 2000), represents a refined approach to the SAR method as first proposed (Murray and Roberts, 1998). For samples that do not exhibit sensitivity changes during the natural OSL measurement, such procedure will provide accurate, high precision $D_{e}$ estimates. We consider it prudent to bracket the natural OSL signal measurement with test doses and to observe the $90-120^{\circ} \mathrm{C} \mathrm{TL}$ and to measure this TL during the low temperature pre-heating following all subsequent test doses. Such an approach simultaneously,

1) allows a check of sensitivity changes during measurement of natural OSL,

2) provides a test of the relationship between $90-120^{\circ} \mathrm{C}$ TL and OSL sensitivity (which in itself is a test of the appropriateness of the post natural measurement OSL sensitivity e.g., Fig. 5), and

3) provides an alternative means of regenerated growth curve normalization (which in many cases may provide improved counting statistics and corresponding improved growth curve forms e.g., Fig. 7).

Our study also demonstrates the importance for systematic studies that quantifies the nature of natural sensitization effects, establishes their relationship to pre-heat and optical stimulation procedures. We have examined a significant set of samples but we need more research into this aspect. 

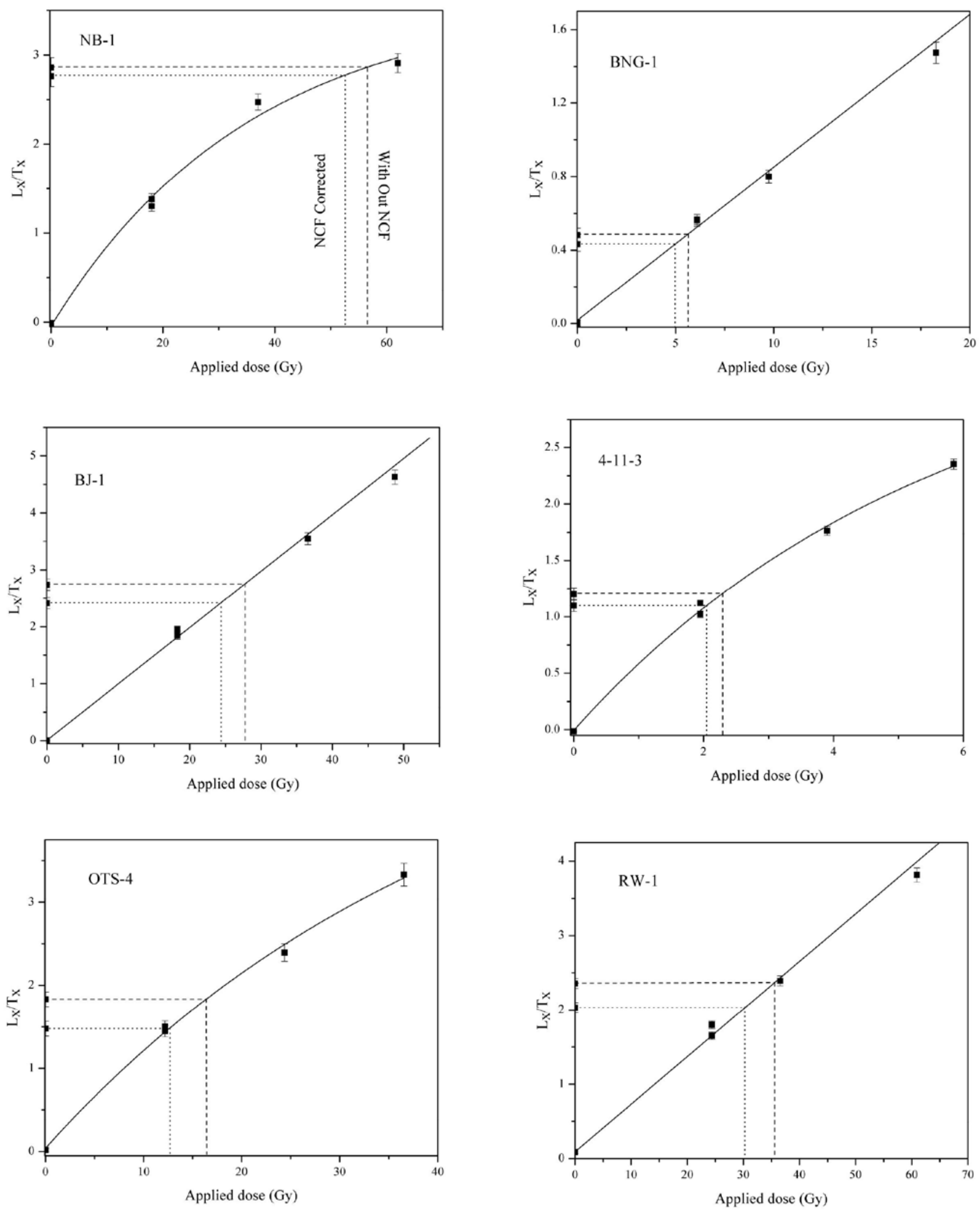

Fig. 7. Comparison of dose values obtained using SAR and without SAR protocol. 
An important outcome of this study is the caution in the use of single grain data as done in an automated single grain reader. This is because the sensitivity of an individual grain cannot be measured easily. It is not yet clear if the brighter grains suffer lesser sensitivity changes but this needs to be probed at a single grain level to decide on the prospects of using single grain ages. These are non trivial measurements on account of low photon yield in TL and OSL of single grains. But a systematic effort is needed. Limited studies that we carried out did not indicate any relationship between sensitivity and sensitivity change.

\section{CONCLUSIONS}

1) Sensitivity changes due to pre-heating and optical stimulation during measurement of natural OSL are omnipresent.

2) The amplitude of such changes may be significant up to $\pm 40 \%$ and could result in large systematic errors in standard SAR $D_{e}$ determinations.

3) Use of $90-120^{\circ} \mathrm{C}$ TL measurements following repeated applications of a test dose provides a means of testing for changes in natural OSL sensitivity.

4) Additionally, comparison of the relationship between OSL and TL responses to a test dose following measurement of natural OSL and those measured following each regeneration cycle, can provide an independent measurement of the appropriateness of the post natural OSL sensitivity correction.

5) We propose the use of a modified SAR procedure (NSC-SAR) that corrects for any changes in sensitivity occurring during the natural measurement cycle. The procedure has no effect on samples that do not exhibit changes in sensitivity during the measurement of natural OSL however, in some cases there may be a shift in the estimated $D_{e}$ of up to $60 \%$.

6) The extent and significance of these effects requires detailed investigation, as it may ultimately serve as a SAR acceptance/rejection criteria for quartz samples.

\section{ACKNOWLEDGEMENTS}

This work was initiated during a Leverhume fellowship to AKS, who thanks Prof DSG Thomas, then at Sheffield University for the facilities. We thank Prof A.G. Wintle for her helpful comments on an earlier version of the manuscript.

\section{REFERENCES}

Bailiff IK, Bowman SGE, Mobbs SF and Aitken MJ, 1977. The phototransfer technique and its use in thermoluminescence dating Journal of Electrostatics 3(1-3): 269-280, DOI 10.1016/03043886(77)90099-7.

Duller GAT, 1991. Equivalent dose determination using single aliquots Nuclear Tracks and Radiation Measurements 18(4): 371-378, DOI 10.1016/1359-0189(91)90002-Y.
Duller GAT, 1995. Luminescence dating using single aliquots: Methods and applications Radiation Measurements 24(3): 217-226, DOI 10.1016/1350-4487(95)00150-D.

Duller GAT, 1996. Recent developments in luminescence dating of quaternary sediments Progress in Physical Geography 20(2): 127145, DOI 10.1177/030913339602000201.

Hansen L, Funder S, Murray AS and Mejdahl V, 1999. Luminescence dating of the last weichselian glacier advance in east greenland Quaternary Science Reviews 18(2): 179-190, DOI 10.1016/S02773791(98)00051-1.

Jain M and Singhvi AK, 2001. Limits to depletion of blue-green light stimulated luminescence in feldspars: Implications for quartz dating Radiation Measurements 33(6): 883-892, DOI 10.1016/S1350-4487(01)00104-4.

Mayya YS, Morthekai P, Murari MK and Singhvi AK, 2006. Towards quantifying beta microdosimetric effects in single-grain quartz dose distribution. Radiation Measurements 41(7-8), 1032-1039, DOI 10.1016/j.radmeas.2006.08.004.

Murari MK, 2008. Component specific luminescence of natural minerals and their application to dosimetry of natural radiation environment. Mohan Lal Sukhadia University, Udaipur, India, unpublished thesis.

Murray AS, 1996. Developments in optically stimulated luminescence and photo-transferred thermoluminescence dating of young sediments: Application to a 2000-year sequence of flood deposits Geochimica et Cosmochimica Acta 60(4): 565-576, DOI 10.1016/0016-7037(95)00418-1.

Murray AS and Mejdahl V, 1999. Comparison of regenerative-dose single-aliquot and multiple-aliquot (SARA) protocols using heated quartz from archaeological sites Quaternary Science Reviews 18(2): 223-229, DOI 10.1016/S0277-3791(98)00055-9.

Murray AS and Roberts RG, 1998. Measurement of the equivalent dose in quartz using a regenerative-dose single-aliquot protocol Radiation Measurements 29(5): 503-515, DOI 10.1016/S13504487(98)00044-4.

Murray AS and Wintle AG, 2000. Luminescence dating of quartz using an improved single-aliquot regenerative-dose protocol Radiation Measurements 32(1): 57-73, DOI 10.1016/S1350-4487(99)00253$\mathrm{X}$

Murray AS, Roberts RG and Wintle AG, 1997. Equivalent dose measurement using a single aliquot of quartz Radiation Measurements 27(2): 171-184, DOI 10.1016/S1350-4487(96)00130-8.

Singhvi AK and Lang A, 1998. Improvements in infrared stimulated dating of partially bleached sediments-the 'differential' partial bleach technique. Ancient TL 16: 63-71.

Stokes S, 1992. Optical dating of young (modern) sediment using quartz: Results from a selection depositional environment Quaternary Science Reviews 11(1-2): 153-159, DOI 10.1016/02773791(92)90057-F.

Stokes S, 1994a. The timing of OSL sensitivity changes in a natural quartz Radiation Measurements 23(2-3): 601-605, DOI 10.1016/1350-4487(94)90106-6.

Stokes S, 1994b. Optical Dating of selected late Quaternary aeolian sediments from the south western United States. Unpublished D. Phil. thesis. Oxford University.

Strickertsson K and Murray AS, 1999. Optically stimulated luminescence dates for late pleistocene and holocene sediments from Norre Lyngby, northern Jutland, Denmark Quaternary Science Reviews 18(2): 169-178, DOI 10.1016/S0277-3791(98)00050-X.

Wintle AG and Murray AS, 1999. Luminescence sensitivity changes in quartz Radiation Measurements 30(1): 107-118, DOI 10.1016/S1350-4487(98)00096-1.

Wintle AG and Murray AS, 2006. A review of quartz optically stimulated luminescence characteristics and their relevance in singlealiquot regeneration dating protocols Radiation Measurements 41(4): 369-391, DOI 10.1016/j.radmeas.2005.11.001. 